\title{
IN-SERVICE FLAW DETECTION AND QUANTIFICATION IN THE COMPOSITE STRUCTURES OF AIRCRAFT
}

\author{
Krzysztof Dragan, Piotr Synaszko \\ Air Force Institute of Technology \\ Warsaw, Poland
}

\begin{abstract}
Taking into consideration the increased usage of composites for aircraft structures there is a necessity for gathering information about structural integrity of such components. During the manufacturing of composites as well as during in service and maintenance procedures there is a possibility for damage occurrence. There is a large number of failure modes which can happen in such structures. These failure modes affect structural integrity and durability. In this work modern approach for detection of composites damage detection such as: delaminations, disbonds, foreign object inclusion and core damage has been presented. This detection is possible with the use of advanced P-C aided Non Destructive Testing methods. In the article nondestructive testing results for the composite vertical tail skins on MiG-29 aircraft will be delivered as well as some results of F-16 horizontal stabilizer and $W-3$ helicopter main rotor blades. Moreover some results of the composite honeycomb and sandwich structures will be presented based on the materials used in the construction of gliders and small aircraft. Factors affecting structural integrity and durability of the composites will be highlighted as well as necessity of the inspection with the use of modern NDT techniques. At the end some effort with Structural Health Monitoring connected with possibility of condition monitoring of composites will be presented.
\end{abstract}

\section{Introduction}

Composite structures become more popular in the aerospace industry. About forty years experiences in sport aviation (mainly gliders structures) composites proved many advantages. The greatest advantage of composite materials is strength and stiffness combined with lightness. Composites by choosing an appropriate combination of reinforcement and matrix material can produce properties that exactly fit the requirements for a particular structure for a load distribution. Composite airframe is usually more integral than metal airframe. Another advantage of composite materials is that they proved design flexibility, for composite doesn't matter that surface what we can do is ruled or not.

Typically single non-destructive method used for inspection of metal structures is not efficient for different types of damages and different construction of composites. Most popular method for NDT of composites is UT with C-scan presentation mode. This method is very good for fast and easy data collection and results of inspections assessment.

\section{Techniques and Types of Damage}

Non destructive testing of MiG's-29 as well as vertical stabilizer's was focused on CFRP (Carbon Fiber Reinforced Plastic) [1]. skin and damages classify as:

- Delaminations- separation between layers of composite;

- Disbonds- lack of adhesive;

- Porosity- poor of resin area;

- Foreign object inclusions- inclusion of non - inherent materials. 
Techniques used for inspection of MiG-29 vertical stabilizer and F-16 horizontal stabilizer are as follows:

\begin{tabular}{|c|c|c|c|}
\hline Technique/Damage & Resonance & Shearography & UT \\
\hline Delamination & - & - & - \\
\hline Disbond & + & $\begin{array}{c}+ \\
\text { (core-skin disbond) }\end{array}$ & + \\
\hline Porosity & - & - & + \\
\hline Foreign Object Include & - & - & + \\
\hline
\end{tabular}

\subsection{Ultrasound Inspection with the Use of Maus ${ }^{\circledR}$ System}

To perform structural integrity test of airplane composite vertical stabilizer, ultrasound testing was delivered. The total surface area for inspection were approximately 11 sq. meters per one aircraft.[1] The aircraft population selected to tests were more than 30. So total area for inspection was more than 360 sq. m Classical tests with use manual hand scanning were very difficult or impossible, because work has been done on the airplane[2]. Automated scanning procedure was applied. MAUS ${ }^{\circledR} V$ system was used. MAUS ${ }^{\circledR}$ system (Mobile Automated System) is an hybrid construction and makes possible inspection with such techniques as: ultrasound, eddy current, MIA, Pitch-Catch, Resonance and with the Phased Array module for ultrasound[2]. System is fully portable and enables inspection on horizontal and vertical inverted surfaces. That is possible due to flexible track system equipped with special handle. On the picture 1 inspection of vertical stabilizer composite skin of MiG-29 is presented.

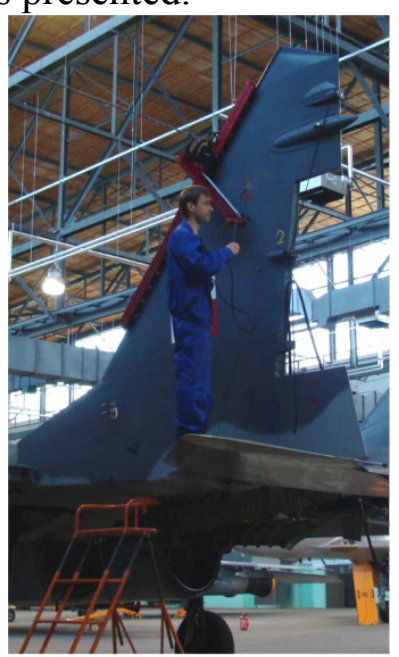

\section{Pic. 1. Composite vertical stabilizer inspection.}

Resonance \& UT inspection with MAUS system are quantitative methods. Results are presented in C-scans mode. MAUS ${ }^{\circledR}$ measurement interface, gives possibility for Amplitude and TOF (Time Of Flight) C-Scan data presentation [2]. On the pictures 2 and $3 \mathrm{C}$-scans (Amplitude C-scan of F-16 horizontal stabilizer and TOF C-scan of MiG - 29 vertical stabilizer) are presented. On the amplitude data different colors are connected with different signal attenuation. Amplitude mode is useful for detection of disbonds. Color range in the TOF data gives information about different composite skin thickness as well as about delamination depth [2]. That system of data presentation is very helpful for damage description as well as for fast damage location finding. If we needs more information about damage we can do additional full waveform capturing with Bscan visualization]. This kind of results is applied for detection of delamination and foreign object inclusion. Typical distribution of damages of vertical stabilizer MiG-29 is a bottom part of stabilizer (Pic. 4). 


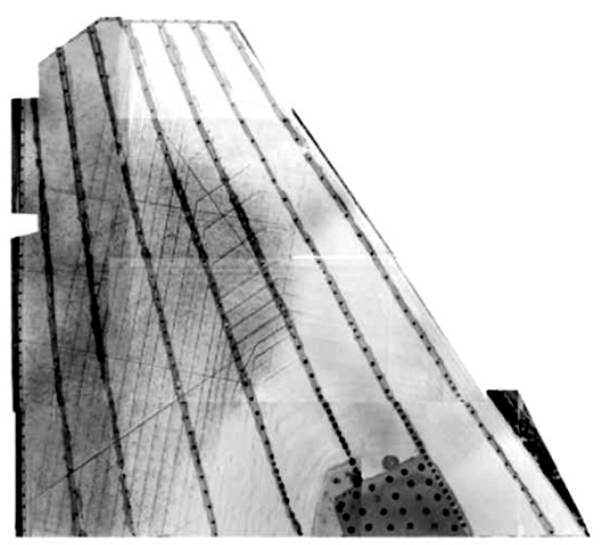

Pic.2. Amplitude C-scan F16 horizontal stabilizer

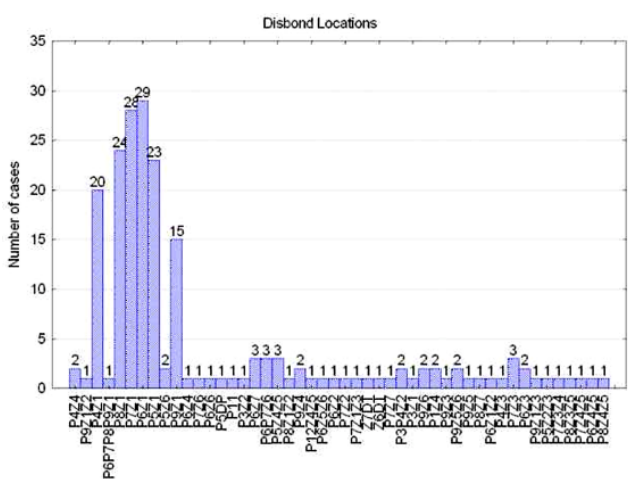

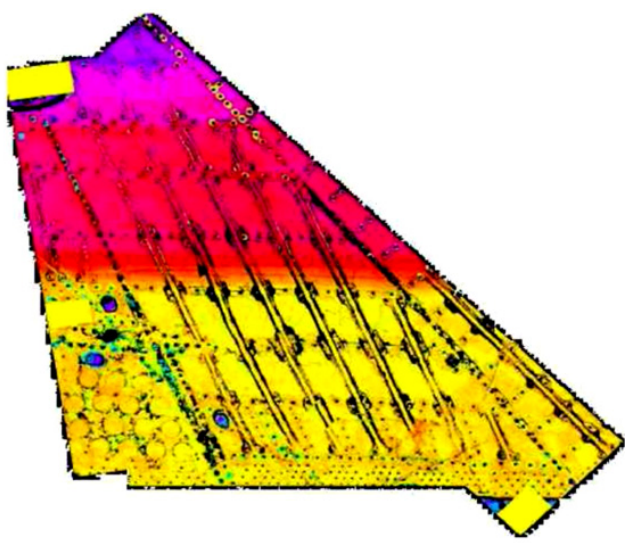

Pic.3. TOF C-scan MiG-29 vertical stabilizer

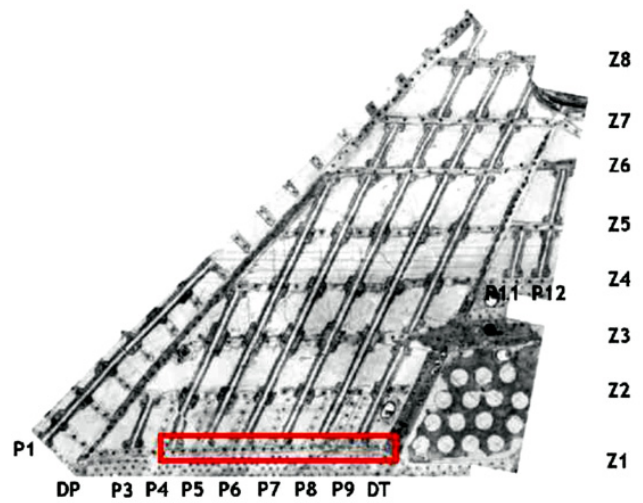

Pic.4. Distribution of damages MiG-29 vertical stabilizer

\section{Inspection of Sandwich Structures}

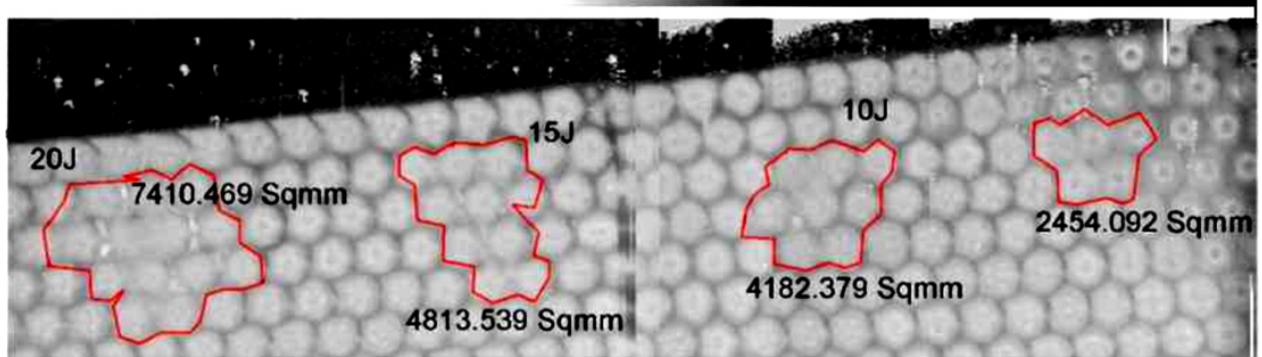

Pic. 5. MIA results main rotor blade inspection

Very effective technique for detection damage in sandwich structure is a Mechanical Impedance Analysis. Second method is a Laser Shearography. This method is very fast and sensitive (specially for thin skin sandwiches) but result is only qualitative (yes/ no). MIA take an answer for a question: is it a damage?

And take information about size of damage. More of NDT application deal with honeycomb sandwich (like a W3 composite main rotor blade inspection Pic.5) [3].Very interesting results to bring inspection wing is B1-PW-5 glider. Skin of this wing is a sandwich with $5 \mathrm{~mm}$ DIVINYCELL foam core. For reason high attenuation of ultrasonic signal in foam core inspection this kind of structure is very difficult [4]. Low frequency signal that we use in MIA methods is much better for foam core inspection. C-scan image give one-valued information about condition of bond line between spar and sandwich skin. Inspection test probe (Pic.6) consists of sandwich panel and laminated spar give us the same result. Additional test probe consists two small disbonds (1 sqmm and $1.5 \mathrm{sqmm}$ ) they are visible in the C-scan (Pic.7). 


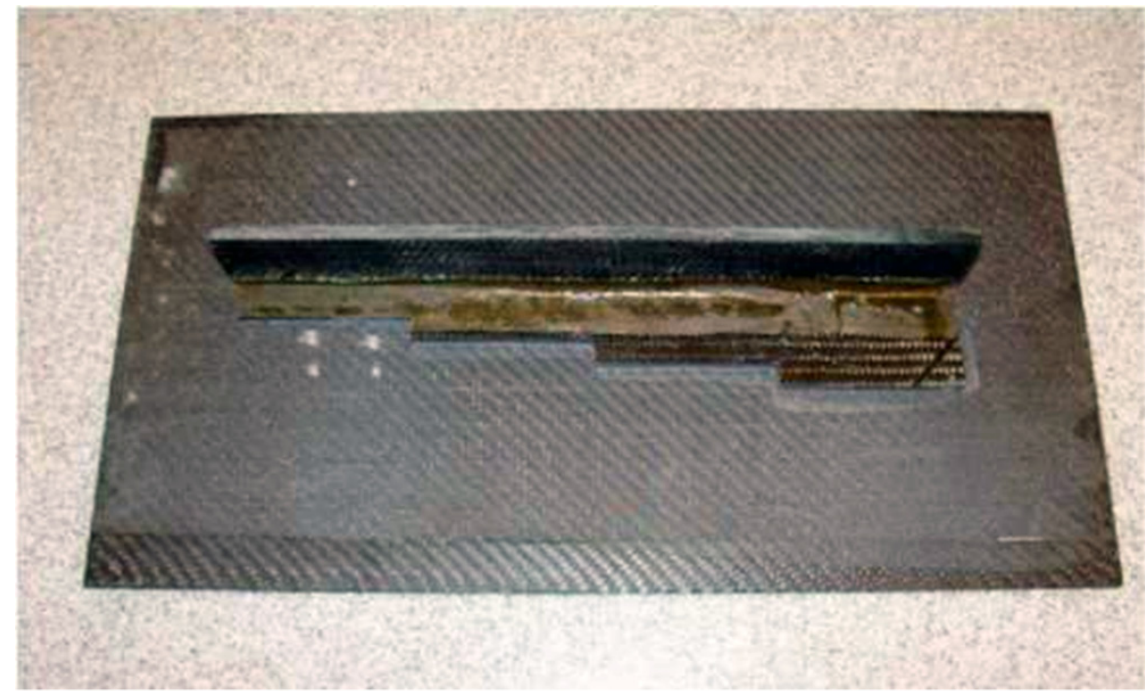

Pic. 6. Test probe

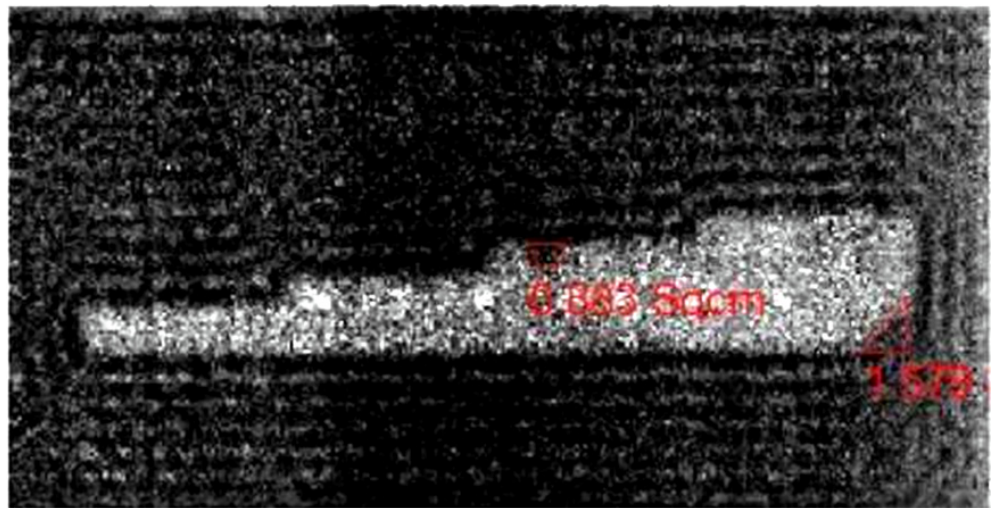

Pic. 7. MIA results test probe

\section{Structural Health Monitoring}

Applying NDT for the composites is necessary from the point of view of their applications not only in the rotorcraft industry but as well in the other aircraft structures. Continuous development of extensive use of composites in the aerospace applications puts great demand for the advanced techniques of NDT as well as for the health monitoring techniques. One of the big advantages of the use of advanced NDT techniques is a possibility to obtain the information about structural integrity of composites without affecting structure properties and collecting data for structure monitoring. One of the disadvantages is a necessity to have the aircraft on the ground, involve human staff and time for inspecting all assumed location [5]. Applying of network sensors distributed in the structure for periodical or even continuous monitoring could affect the time necessary for the inspection. The so called Structural Health Monitoring SHM gives a possibility to deploy NDT with greater access to more complex structures. According to D. Roach "The core of SHM it is development of self-sufficient systems, that use built-in distributed sensors/actuators not only to detect structural failures but to monitor the effects of structural usage" [5].

Using sensors networks could be realized in three approaches which are listed below [5]:

- In-situ sensors;

- Sensors network with in-situ data acquisition;

- Sensors network with real-time data transmission to remote site.

In the first group sensors are permanently installed in the structure. For the diagnostic purposes aircraft must be on the ground. All necessary items like power supply, data acquisition electronics must be delivered to the aircraft. All sensors are connected to the connector and data analysis and 
detection procedures are performed on-site. From that point of view manual or automated collecting data are substituted by distributed networks. In the second group distributed networks are equipped with the electronics and memory to record and to store data. ,,Those items are equipped with programmable circuits having the power for automated data logging in flight or on the ground" [5]. Data must be gathered by the technical staff during the aircraft stay on the ground.

The third group is quite similar to the second group. The only difference is the usage of communication system application. That system enables wireless transmission of collected data. For that particular application software could be developed to send data to maintenance personnel.

There is a lot of work which is dedicated to possibility of applying SHM especially to aircraft as well as to composites. The use of in-situ sensors for the SHM of aircrafts seems to be viable option in the near future [5].

\section{Summary}

In the article approach for inspection as well as some obtained results are presented. All performed inspections were ISI (In Service Inspection). Main problem was working on the horizontal surfaces with bolt and rivets areas disturbing to attach flexible track system. Also with the first inspection data assessing was slightly difficult (it was first inspection in Polish Air Force). Gained experience during aircraft inspection and amongst other for composite skin allows for on condition maintenance.

Automated inspection increased reliability and speed of inspection reducing so called "human factor" during the measurement. As you can notice in the chart presenting damages location distribution, it occurred in random position. From that point of view there is necessity for periodical inspection of composite skin of vertical stabilizers. In the face of future planes connected with Air Force development gained experience gave us potential to work with new aircrafts introduced to Armed Forces.

Air Force Institute of Technology is R\&D center supplying solution for Polish Army mainly connected with aging aircraft program. That role was presented on the base of introducing new maintenance approach for the MiG-29 aircraft as well as F-16.

\section{References}

1. FAA. (2000, January). Probabilistic Design of Damage Tolerant Composite Aircraft Structures. Office of Aviation Research Washington. (DOT/FAA/AR-01/55)

2. Dragan, K., \& Klimaszewski, S. (2006) In-service Flaw Detection and Quantification on the MiG-29 Composite Vertical Tail Skin. In: Proceedings of the $9^{\text {th }}$ European Conference on Non Destructive Testing, 25-29 September 2006, Berlin.

3. Dragan, K., \& Klimaszewski, S. (2008). Holistic Approach for Structural Integrity Evaluation of Composite Main Rotor Blades. In: Proceedings of the $17^{\text {th }}$ World Conference on Non Destructive Testing, 26-31 August 2008, Shanghai.

4. Synaszko, P., Dragan, K., \& Salacinski, M. (2008). Badania nieniszczqce kompozytowych struktur szybowca PW-5. In: Proceedings of the $37^{\text {th }}$ National Conference on Non-Destructive Testing, 21-23 October 2008, Sobieszewo.

5. Roach, D. (2007, January). Smart Aircraft Structures: a Future Necessity. High Performance Composites, 15(1), 28-30. 